\title{
Parent Perception of Their Child's Asthma Control and Concurrent Complementary and Alternative Medicine Use
}

\author{
Michael D. Cabana, M.D., M.P.H., ${ }^{1-3}$ Anurekha Gollapudi, ${ }^{1}$ Leah G. Jarlsberg, ${ }^{1}$ Megumi J. Okumura, M.D., ${ }^{1}$ \\ Michelle Rait, M.A., ${ }^{1}$ and Noreen M. Clark, Ph.D. ${ }^{4}$
}

We conducted a cross-sectional survey of 1322 parents of children with asthma to measure the prevalence and factors associated with complementary and alternative medicine (CAM) use for pediatric asthma. Multivariate regression techniques were used to determine factors associated with CAM use. Eleven percent (141/1322) of children were given CAM. Parents of children on daily medications who were perceived to have poor asthma control were almost three times more likely to use CAM than parents of children on no daily medications who were perceived to have high asthma control (risk ratio: $=2.81$; confidence interval: $1.72,4.60$ ); age, gender, race, income, and education level were not significant independent predictors. Parent perception of asthma control is significantly associated with CAM use. It is important for providers to elicit information regarding CAM use in the clinic, as this may imply that the asthma symptoms may not be well controlled.

\section{Introduction}

$\mathrm{T}$ HE USE OF COMPLEMENTARY and alternative medicine (CAM), defined as practices, products and health-care systems that are not usually included or delivered in traditional medical systems, ${ }_{1}^{1}$ has become more prevalent for children. ${ }^{2}$ Studies have noted higher CAM use for children with asthma or respiratory symptoms.,4 Furthermore, several cross-sectional studies of CAM use for children with asthma in multicultural communities ${ }^{5-7}$ have reported a prevalence of CAM use as high as $89 \%$.

Given the prevalence of asthma and the increasing use of CAM, it is not unusual for primary care clinicians to deal with both issues. A key step in management is identifying CAM attitudes and practices and discussing how such therapies may affect conventional asthma medicines. In some cases CAM interventions for asthma and allergic disease have been associated with increased hospitalizations, ${ }^{8}$ adverse events, ${ }^{9}$ or potentially dangerous interactions of CAM therapies such as ephedra with albuterol causing cardiovascular effects. ${ }^{10}$ Use of CAM may also potentially affect adherence to conventional medical therapies. ${ }^{11}$

Despite the importance of these issues, communication about CAM use is not ideal, as few health-care providers are aware of parent CAM use for their children. ${ }^{1,3,6}$ Furthermore, although motivations for adult patients to use CAM have been explored, there is relatively little understanding of the factors associated with and potential motivation for CAM use in children.

In this study, we interviewed a cross-section of parents of children with asthma to examine CAM use for pediatric asthma. Unlike previous studies, the families involved in this study represent a variety of practice settings (rural, urban, and suburban). The purpose of this study was to measure the prevalence of CAM use and the factors associated with CAM use for pediatric asthma.

\section{Materials and Methods}

We analyzed baseline data from a randomized clinical trial designed to evaluate the effect of physician asthma education on provider adherence to National Heart Lung and Blood Institute (NHLBI) guidelines for the management of asthma in children. The institutional review boards of the University of Michigan and the University of California, San Francisco approved the study protocol. Analyses from this dataset have been used to examine parent attitudes regarding asthma management, as well as to validate a "Beliefs in Medications" questionnaire. ${ }^{12,13}$

${ }^{1}$ Department of Pediatrics, ${ }^{2}$ Department of Epidemiology and Biostatistics, and ${ }^{3}$ Institute for Health Policy Studies, University of California, San Francisco School of Medicine, San Francisco, California.

${ }^{4}$ Center for the Management of Chronic Disease, Ann Arbor, Michigan.

The authors declare no competing interest. 


\section{Patient population}

We developed a registry of patients with asthma from the patient panels of pediatricians involved in the study. Project staff successfully contacted the adult-usually responsible for the child's health-related care and who takes him/her to the doctor-of 3263 patients by telephone to invite further study participation, answer questions, obtain informed consent, and screen for eligibility. Of the 3263 patients whose parents could be contacted, 1858 met eligibility criteria.

Eligibility criteria included being the patient of a study physician, having a diagnosis of asthma and having utilized health-care services in the preceding 2 years, being between 2 and 12 years of age, and having no other diseases associated with pulmonary complications, such as tuberculosis, sickle cell disease, or cystic fibrosis. We included only one child per family. We excluded children if they had a parent who worked for a study physician or if children were under 2 years of age, given that the diagnosis of asthma can be difficult to establish before age 2 .

Parents/guardians of 1322 of the 1858 eligible patients agreed to participate, yielding a response rate of $71.2 \%$. Baseline interviews were conducted with these 1322 parents between May 2004 and April 2005.

\section{Data collection}

Trained interviewers administered the baseline survey to parents by telephone. The telephone interview averaged $20 \mathrm{~min}$ in duration and was conducted in English for the majority of parents. It was also conducted in Spanish, Arabic, and Bengali in the relatively few instances when it was necessary. As part of this survey, parents were asked to provide demographic information including patient age, race, gender, and insurance type; the total annual combined household income in categories of $\sim \$ 10,000$ increments; the number of persons dependent on this income; and the highest level of school completed. To determine asthma severity, parents were asked about symptom frequency: (1) "In the past month, how many nights have symptoms such as coughing, wheezing, chest tightness, or shortness of breath interfered with (child's) sleep?" and (2) "In the past month, how many days have symptoms such as coughing, wheezing, chest tightness, or shortness of breath interfered with running, playing games or sports?"14

To determine the parents' perception of their child's current asthma control, we asked parents to rate, "how controlled has your child's asthma been over the last month (28 days)" using a scale from 1 to 5 , where 1 was "not controlled at all" and 5 was "very controlled."

Parents were asked to list each asthma medication currently prescribed by a physician. To gather data on the prevalence of use of complementary and alternative medicine, parents were also asked the following question: "In the past 12 months, have you used alternative home remedies, including herbs, teas, dietary changes, breathing exercises, meditation, prayer, massage, biofeedback, or homeopathy to control [your child]'s asthma symptoms?"

\section{Classification of CAM therapies}

To classify parent responses into CAM categories, two investigators examined the verbatim responses of each of the parents who indicated use of alternative medicine using the National Institutes of Health National Center for Complementary and Alternative Medicine classification system (Table 1). These categories included alternative medical systems, mind-body interventions, biologically based therapies, manipulative and body-based methods, and energy therapies. In a handful of cases, parents described two CAM therapies as a single therapy. In these cases, the therapy was classified in relation to the initial therapy described. Responses that were consistent with conventional therapies for asthma (e.g., use of air filters, allergen avoidance, exercise, etc.) were excluded from further classification (Table 2). Although breathing exercises are used for vocal cord dysfunction associated with asthma, none of the patients in our sample reported this condition.

\section{Variables}

Our dependent variable was the use of CAM for asthma. Independent variables included patient characteristics (age, gender, and severity of asthma), parent perception of the child's asthma control, current asthma management (name and type of daily medication used), and caregiver characteristics (age, ethnicity, race, location of birth, income, education level, and insurance status).

We dichotomized the level of caregiver education by collapsing responses into one of two categories, "college graduate" versus "noncollege graduate." The variable for race was collapsed into white and nonwhite. We used the definition of poverty published by the United States Department of Health and Human Services in 2004 to determine whether

Table 1. Frequency of Complimentary and Alternative Medicine (CAM) Use, by Category

\begin{tabular}{lc}
\hline Type of CAM & $N(\%)$ \\
\hline Biologically based therapies & $78(42)$ \\
Caffeine/coffee & 6 \\
Essential oils & 8 \\
Herbs & 15 \\
Vitamin/mineral supplements & 20 \\
Teas & 27 \\
Other foods & 2 \\
Mind-body interventions & $73(39)$ \\
Breathing exercises & 23 \\
Creative visualization & 1 \\
Meditation & 3 \\
Prayer & 40 \\
Relaxation techniques & 4 \\
Yoga & 2 \\
Manipulative and body-based methods & $24(13)$ \\
Chiropractor & 8 \\
Contact reflexology & 1 \\
Cranio-sacral therapy & 3 \\
Massage & 10 \\
Percussions & 1 \\
Strain-counter-strain therapy & 1 \\
Alternative medical systems & $12(6)$ \\
Homeopathy & 12 \\
Energy-based methods & 0 \\
\hline
\end{tabular}


TAble 2. Therapies Described by FAmilies, BUt not InCluded in Complimentary and Alternative MEDiCINE TAXONOMY

\begin{tabular}{lc}
\hline Therapies & $N(\%)$ \\
\hline Allergen avoidance (no pets, frequent cleaning) & 19 \\
Improved air quality (HEPA filters) & 17 \\
Climate control & 38 \\
Humidifier/vaporizer & 2 \\
Dehumidifier & 12 \\
Cold air/vapor (puts head in freezer) & 64 \\
Warm baths, showers, steam & 2 \\
Moved (different home or school) & 4 \\
Unspecified & 12 \\
Dietary changes & 15 \\
Eliminations (dairy, fat, Teflon, pesticide) & \\
Unspecified & 4 \\
Exercise/activity changes & 5 \\
Reduction & \\
Increase & \\
Physical manipulation & 4 \\
Nonprofessional massage & 1 \\
Pounding & 4 \\
Posture adjustments (propping up on pillows) & 2 \\
Other (hot water bottle, warm towels) & 42 \\
Over-the-counter medicines & \\
\hline
\end{tabular}

HEPA, high efficiency particulate air.

household income was above or below the poverty level, adjusting for the number of household members dependent on the reported income..$^{15}$ We created the following six categories: income less than the Federal Poverty Line (FPL), income greater or equal to the FPL and less than two times the FPL, income greater or equal to twice the FPL and less than three times the FPL, etc. until a category of income greater than five times the FPL.

We categorized each patient based on the use of a daily controller medication versus no daily controller medication. Controller medications included daily inhaled corticosteroids, leukotriene modifiers, long-acting $\beta$-agonists, and combination medications.

Based on inspection of the data, we dichotomized the level of caregiver perception of their child's asthma into one of two categories, "not controlled," if they rated the child's asthma control as 1-3; versus "controlled," if they rated the child's asthma control as 4 or 5 .

\section{Analysis}

Categorical variables were compared using the $\chi^{2}$ statistic or, where expected cell counts were less than five, Fisher's exact test Table 3. Means of continuous variables (child age, caregiver age) were compared using Student's t-test. Multivariate logistic regression was performed with use of CAM as the dependent variable, controlling for the following independent variables: child gender, use of a daily controller medicine, caregiver perception of asthma control, and caregiver age, race, place of birth, income relative to the poverty line, education, and insurance coverage.

We used a generalized estimating equation (GEE) to control for correlated or clustered responses among patients of the same physician. All statistical analyses were performed using SAS Version 9.1 software (SAS Institute, Cary, NC). Statistical significance was defined as $p<0.05$.

\section{Results}

Characteristics of the 1322 children, their caregivers, and their households are presented in Table 3.

\section{Frequency and perceived effects of CAM use}

Of the 1322 children, 141 (10.7\%) had been given CAM for their asthma in the last year. The 141 caregivers described 187 different examples of CAM, for an average of 1.3 instances of CAM use for asthma per family.

Table 1 provides categories of CAM use, the frequency with which each was cited, and examples. There were an additional 247 examples of therapies, initially described by parents as CAM (Table 2). However, these therapies did not fall into CAM definitions and were excluded from further analysis.

For the 187 examples of CAM use, in over two-thirds of the cases $(68 \%)$, the therapy was self-recommended (Table 4$)$. For $13 \%$ of cases of CAM use, caregivers stated that a medical practitioner, not necessarily the child's physician, had made the CAM recommendation. The high frequency of selfreferral for CAM was consistent by type of CAM category.

When asked about the effects of CAM use, in $88 \%$ of instances of CAM use, caregivers reported a positive effect. Although in one-third of cases (68 of 187 cases) the positive effect was unspecified, in many cases caregivers reported changes in relief of asthma or respiratory symptoms, a "calming effect" or a perception that the CAM use prevented future asthma exacerbations or symptoms.

\section{Factors associated with CAM use}

We explored an interaction between parent's perception of the child's asthma control and the use of a daily controller medication, as the likelihood of CAM use might be associated with the presence of poor asthma control, despite the use of a daily controller medication. In the adjusted model, using GEE to control for correlated responses among patients of the same physician, the single independent predictor of CAM use was the use of a daily medication with perceived poor asthma control [odds ratio (OR): 2.81; 95\% confidence interval (CI): 1.72, 4.60]. No other demographic characteristics were associated with CAM use for asthma (Table 5).

We repeated our analysis with the use of biologicallybased CAM (e.g., herbs, teas, and supplements) for asthma as the dependent variable. This type of CAM use may be more likely to be implicated for interactions with conventional asthma therapies. In this model, increasing age of the patient (OR: 1.11; 95\% CI: 1.05, 1.17), in addition to the use of a daily asthma controller with perception of poor asthma control (OR: 2.26; 95\% CI: 1.09, 4.68), was associated with increased likelihood of CAM use. No other variables were significant.

\section{Discussion}

In our sample, one in nine parents with a child with asthma reported CAM use within the last year. In addition, no demographic factors were associated with CAM use for 
Table 3. Use of Complimentary and Alternative Medicine (CAM) by Caregiver ANd Household Characteristics

\begin{tabular}{|c|c|c|}
\hline & Used CAM N (\%) & $\begin{array}{c}\text { Bivariate, unadjusted } \\
\text { RR }(95 \% \mathrm{CI})\end{array}$ \\
\hline Caregiver age (odds per 5 additional years) & $38.7 \pm 7.4$ & $1.06(0.94-1.20)$ \\
\hline \multicolumn{3}{|l|}{ Caregiver ethnicity $(n=1317)$} \\
\hline Hispanic/Latino origin & $2 / 35(6)$ & $0.53(0.14-2.04)$ \\
\hline Not of Hispanic/Latino origin & $139 / 1282(11)$ & \\
\hline \multicolumn{3}{|l|}{ Caregiver race $(n=1303)$} \\
\hline Asian & $7 / 36(19)$ & $2.27(0.97-5.30)$ \\
\hline Black & 26/161 (16) & $1.81(1.13-2.88)$ \\
\hline Other/mixed & 6/57 (11) & $1.10(0.46-2.64)$ \\
\hline White & $101 / 1049(10)$ & Reference \\
\hline \multicolumn{3}{|l|}{ Caregiver place of birth $(n=1321)$} \\
\hline Foreign born & 10/86 (12) & $1.10(0.60-2.01)$ \\
\hline US born & $131 / 1235(11)$ & \\
\hline \multicolumn{3}{|l|}{ Primary language at home $(n=1321)$} \\
\hline English & $138 / 1279(11)$ & $1.51(0.50-4.55)$ \\
\hline Other & $3 / 42(7)$ & \\
\hline $\begin{array}{l}\text { Mean household income level (odds per } \\
\text { each multiple over the FPL) }\end{array}$ & $4.2 \pm 1.7$ & $0.89(0.80-0.99)$ \\
\hline \multicolumn{3}{|l|}{ Education level $(n=1315)$} \\
\hline Some college/AA/trade school or less & $78 / 686(11)$ & $1.14(0.83-1.55)$ \\
\hline College graduate or more & $63 / 629(10)$ & Reference \\
\hline \multicolumn{3}{|l|}{ Insurance coverage $(n=1307)$} \\
\hline No insurance/self-pay & $0 / 18(0)$ & $0.25(0.02-3.84)$ \\
\hline Medicaid & 23/187 (12) & $1.16(0.76-1.77)$ \\
\hline Private or other insurance & 118/1114 (11) & Reference \\
\hline
\end{tabular}

CI, confidence interval; FPL, Federal Poverty Line; RR, risk ratio.

asthma. As a result, health-care providers should not make assumptions about which families use CAM, but instead evaluate potential CAM use in all families. We also found that one factor that is associated with CAM use is the parent perception of control of asthma symptoms. If parents' perceive that their child's asthma control is poor and the child is already taking a daily asthma medication, the likelihood of CAM use for asthma is significantly increased.

Our estimates of CAM use for asthma are less than other reported studies. ${ }^{5-7}$ However, although these studies also focused on children with asthma, the samples were drawn from single, multicultural communities within large cities. Our estimate of CAM use for asthma is consistent with other broader, representative samples. ${ }^{16,17}$ Our sample was drawn from three counties in Southeastern Michigan, which offer a cross-section of different practice settings (rural, suburban, urban, and small cities). Although Sidora-Arcoleo

Table 4. Source of Complimentary and Alternative Medicine Use Recommendation, by Category

\begin{tabular}{lc}
\hline & $N(\%)$ \\
\hline All therapies & 187 \\
Self & $128(68)$ \\
Medical practitioner & $25(13)$ \\
Other & $30(16)$ \\
Missing & $4(2)$ \\
\hline
\end{tabular}

et al. reported a higher prevalence of CAM use for asthma compared to our analysis (65\% versus $11 \%$, respectively) in a population from a similar but smaller cross-section of settings, ${ }^{18}$ our analyses excluded over-the-counter medications as a type of biologically based CAM.

In multivariate analysis, we found that no demographic factors are associated with parental report of CAM use for their child. One reason may be the broad definition of CAM, which ranges from mind-body interactions (e.g., prayer, etc.) to biologically based interventions (e.g., herbs, etc). We repeated the analyses with CAM use limited to only biologically based interventions and found no overall difference in our results.

Another factor that may explain why CAM use is also independent of demographic characteristics was the fact that we controlled for parent perception of asthma control. Parental perception of asthma control is independent of any demographic characteristic, and is a reflection of the underlying asthma severity and the perceived success of current management. ${ }^{19}$

Furthermore, there was effect modification of the perception of asthma control through an interaction with the child's current use of daily asthma medications. If parents perceive that their child's asthma control is poor and the child was already taking a daily asthma medication, the likelihood of CAM use for asthma was significantly increased, more than each single factor alone. This finding is similar to patterns observed for older patients, as adults with self-reported poorer health status were more likely to use CAM. ${ }^{20}$ 
Table 5. Logistic Regression Model: Odds of Complimentary and Alternative Medicine USE FOR AsTHMA

\begin{tabular}{lc}
\hline & $\begin{array}{c}\text { Adjusted OR } \\
(95 \% \text { CI })\end{array}$ \\
\hline $\begin{array}{l}\text { Male } \\
\text { Child age (odds per additional year) }\end{array}$ & $0.80(0.57-1.12)$ \\
Daily meds $\times$ perception of control & $1.03(0.99-1.07)$ \\
On daily meds, symptoms not & $2.81(1.72-4.60)$ \\
$\quad$ controlled & \\
No daily meds, symptoms not & $1.53(0.64-3.64)$ \\
$\quad$ controlled & \\
On daily meds, symptoms controlled & $1.38(0.96-1.97)$ \\
No daily meds, symptoms controlled & Reference \\
Caregiver income level & $0.90(0.80-1.00)$ \\
Education level & \\
High school graduate or less & $0.72(0.40-1.30)$ \\
Some college or more & Reference \\
Caregiver race & \\
Asian & $1.50(0.45-5.03)$ \\
Black & $1.50(0.85-2.66)$ \\
Other/mixed & $1.12(0.38-3.29)$ \\
White & Reference \\
\hline
\end{tabular}

$\mathrm{CI}$, confidence interval; Meds, medicines; OR, odds ratio.

These findings have implications for clinical care. The NHLBI guidelines recommend that physicians develop a partnership with families and attempt to screen for parent concerns about asthma. ${ }^{15}$ For example, health-care providers can ask, "how well controlled do you think your child's asthma is?" If the level of asthma control is a concern, healthcare providers can initiate further management and develop a concrete plan to specifically address this issue. Studies suggest that use of simple, direct communication techniques to address parent questions and improve adherence do not necessarily require additional clinician time during the visit. ${ }^{21}$ If parent concerns are not addressed, there is a lower likelihood of adherence. ${ }^{22}$ This study would also suggest that such parents may be more likely to try CAM therapies for their child's asthma. In two-thirds of cases, CAM use for asthma was initiated by the parents themselves.

\section{Limitations}

Despite the cross-section of practice settings in our sample, our data were only from Southeastern Michigan, which may not be generalizable. We did not collect information about previous parental CAM self-use, which has been shown to be associated with parental use of CAM for their children. Although this variable is not in our analyses, it is unlikely to affect key variables in the analyses, such as parent perception of asthma severity or physician prescription of a daily asthma controller medication.

Finally, according to the NHLBI guidelines, asthma control is based on objective pulmonary function tests, as well as parent description of symptom frequency. ${ }^{14}$ In addition, with there are other questionnaires to systematically assess asthma control, ${ }^{19}$ we did not collect lung function data or utilize other questionnaire methods. As a result, we were unable to correlate patient perception of control with objective severity measures or other measures of asthma control.

\section{Conclusions}

This study offers additional insight into potential motivation for parent use of CAM for their children, as parent's perception of asthma control is significantly associated with CAM use. In developing a rapport with parents, it is important to elicit parent concerns and address perceptions of asthma control. No demographic factors were associated with general CAM use. As a result, health-care providers should not make assumptions and should screen and assess all families about potential CAM use, as well as be prepared to address how CAM use may affect current asthma management.

\section{Acknowledgments}

Portions presented in part at the American Thoracic Society Annual Meeting; San Francisco, CA, May 20, 2007 and the Pediatric Academic Societies Meeting, Toronto, Ontario, May 5, 2007. The authors thank Ms. Minal Patel for her editorial assistance. This work was funded by a grant from the National Heart, Lung and Blood Institute (HL070771).

\section{References}

1. Eisenberg DM, Kessler RC, Foster C, Norlock FE, Calkins DR, Delbacno TL. Unconventional medicine in the United States: prevalence, costs and patterns of use. N Engl J Med 1993; 328:246-252.

2. Ernst E. Prevalence of complementary alternative medicine for children: a systematic review. Eur J Pediatr 1999; 158:7-11.

3. Ottolini MC, Hamburger EK, Loprieato JO, Coleman RH, Sachs HC, Maden R, Brasseux C. Complementary and alternative medicine use among children in the Washington, DC area. Ambul Pediatr 2001; 2: 122-125.

4. Pitetti R, Singh S, Hornyak D, Garcia SE, Herr S. Complementary and alternative medicine use in children. Ped Emerg Care 2001; 17:165-169.

5. Mazur LJ, deYbarrondo L. Use of alternative and complementary therapies for pediatric asthma. Tex Med 2001; 97:64-68.

6. Braganza S, Osuah PO, Sharif I. The use of complementary therapies in inner-city asthmatic children. J Asthma 2003; 40:823-827.

7. Reznik M, Osuah PO, Franco K, Cohen R, Motlow F. Use of complementary therapy by adolescents with asthma. Arch Pediatr Adolesc Med 2002; 156:1042-1044.

8. Blanc PD, Kuschner WG, Katz PP, Smith S, Yellin EH. Use of herbal products, coffee or black tea and over-the-counter medications as self-treatments among adults with asthma. J Allergy Clin Immunol 1997; 100: 789-791.

9. Bielory L. Complementary and alternative interventions in asthma, allergy and immunology. Ann Allergy Asthma Immunol 2004; 93: s45-s54.

10. Lasnski SL, Greenwald M, Perkins A, Simon HK. Herbal therapy use in a pediatric emergency department population: expect the unexpected. Pediatrics 2003; 111:981-985.

11. George M, Brick K, Hufford DJ, Jemmott LS, Weaver TE. Beliefs about asthma and complementary and alternative medicine in low-income inner-city African-American adults. I Gen Intern Med 2006; 21:1317-1324.

12. Orrell-Valente JK, Jarlsberg LG, Rait MA, Thyne SM, Rubash T, Cabana MD. Parents' specific concerns about daily asthma medications for children. J Asthma 44:385-390.

13. Conn KM, Halterman JS, Lynch K, Yoos HL, Cabana MD. The impact of parent's medication beliefs on asthma management. Pediatrics 120:e521-e526. 
14. Guidelines for the Diagnosis and Management of Asthma. National Heart, Lung, Blood Institute, Expert Panel Report II. Public Health Service; NHLBI publication 97-4051. Bethesda, MD: National Institutes of Health, 1997.

15. The 2004 United States Department of Health and Human Services Poverty Guidelines. Available at: http://aspe.hhs.gov/ poverty/04poverty.shtml. Accessed June 20, 2006.

16. Davis MP, Darden PM. Use of complementary and alternative medicine by children in the United States. Arch Pediatr Adolesc Med 2003; 157:393-396.

17. Spigelblatt L, Laine-Ammara G, Pless IB, Buyver A. The use of alternative medicine by children. Pediatrics 1994; 94:811-814.

18. Sidora-Arcoleo K, Yoos HL, McMullen A, Kitzman H. Complementary and alternative medicine use in children with asthma: prevalence and sociodemographic profile of users. J Asthma 2007; 44:169-175.

19. Yawn B, Breneman S, Ramey-Allen F, Cabana MD, Markson L. The assessment of asthma severity and asthma control in children. Pediatrics 2006; 118:322-329.
20. Astin JA. Why patients use alternative medicine: results of a national study. JAMA 1998; 279:1548-1553.

21. Cabana MD, Slish KK, Evans D, Mellins RB, Brown RW, Lin X, Kaciroti N, Clark NM. Impact of physician asthma care education on patient outcomes. Pediatrics 2006; 117:2149-2157.

22. Clark NM, Norhwehr F, Gong M, Evans D, Maiman LA, Hurwitz ME, Roloff D, Mellins RB. Physician-patient partnership in managing chronic illness. Acad Med 1995; 70:957-959.

$$
\begin{array}{r}
\text { Address reprint requests to: } \\
\text { Dr. Michael D. Cabana } \\
\text { Division of General Pediatrics } \\
3333 \text { California Street, Laurel Heights Campus \#245 } \\
\text { San Francisco, CA } 94118 \\
\text { E-mail: michael.cabana@ucsf.edu }
\end{array}
$$

Received for publication May 15, 2008; accepted after revision September 30, 2008. 